\title{
Tratamento dos sulcos palpebromalar e nasojugal com ácido hialurônico
}

\author{
Treatment of tear trough deformity with hyaluronic acid gel filler
}

Giovanni André Pires Viana ${ }^{1}$, Midori Hentona Osaki ${ }^{1}$, Angelino Júlio Cariello ${ }^{1}$, Renato Wendell Damasceno ${ }^{1}$

\section{RESUMO}

Objetivo:Verificar a eficácia do preenchimento dos sulcos nasojugal e pal pebromalar deprimidos através da injeção de ácido hialurônico e analisar as complicações observadas.

Métodos: Foi realizado um estudo piloto, prospectivo, aprovado pelo Comitê de Ética em Pesquisa da Universidade Federal de São Paulo, com pacientes recrutados no Serviço de Plástica Ocular do Departamento de Oftalmologia da UNIFESP/EPM. Foram selecionados pacientes de ambos os sexos, com idade entre 25 e 60 anos, que apresentavam os sulcos nasojugal e/ou palpebromalar deprimidos, que não haviam sido submetidos à cirurgia na pálpebra inferior nem apresentavam histórico de trauma nesse local. O ácido hialurônico foi aplicado via transcutânea e depositado na região supraperiosteal em pequenos volumes. Todo paciente foi tratado pelo mesmo cirurgião (GAPV), tendo sido examinado no pós-operatório em intervalos regulares e fotografado no pré-operatório, no pós-operatório imediato, na $4^{\underline{a}}$ semana, no $6^{\circ}$ e no $12^{\circ}$ mês após o procedimento. Ao final deste período todas as fotos foram analisadas por profissional não ligado a esta pesquisa, visando verificar a eficiência da técnica em atingir seus objetivos.

Resultados: Entre junho e agosto de 2008, 10 pacientes foram incluídos neste estudo piloto. Oito pacientes foram tratadas uma única vez, enquanto duas precisaram de retoque na $4^{\underline{a}}$ semana após a aplicação inicial. O volume injetado foi em média de 0,61 $\mathrm{ml}(\mathrm{DP}=0,25)$ no lado direito e de $0,65 \mathrm{ml}(\mathrm{DP}=0,26)$ no lado esquerdo. As complicações observadas foram equimose em 6 casos, edema local maior que 48 horas em um paciente e lesão cutânea semelhante à acne em um participante.

Conclusões: $O$ estudo piloto demonstrou que o tratamento dos sulcos nasojugal e pálpebro-malar com uso de ácido hialurônico se mostrou eficaz e previsível, com alto nível de satisfação dos pacientes e com resultado duradouro.

Descritores: Ácido hialurônico/administração \& dosagem; Ácido hialurônico/efeitos adversos; Pálpebras/cirurgia; Resultado de tratamento; Face/cirurgia; Técnicas cosméticas

\begin{abstract}
Background: Volume loss and muscular hyperactivity are two major components of the aging process that contribute to the formation of the folds and wrinkles. Tear trough deformity is one of the most difficult depressions to correct surgically.

Purpose: The aim of this study was to evaluate the results of ten patients submitted to periorbital filling with hyaluronic acid gel filler.

Methods: Between June and August, 2008, 10 patients have had their tears troughs treated with hyaluronic acid gel filler. The filler was introduced by a serial puncture technique and approximately $0.1 \mathrm{~m} /$ was injected at each pass. The filler was placed in the pre-periosteal tissue. Patients photographs before and after the procedure were reviewed to assess the outcomes.

Results: The mean volume per side needed to achieve correction was on the right side $0.61 \mathrm{ml}(S D=0.25)$ and on the left side $0.65 \mathrm{ml}(S D=0.26)$. The most common complications were bruising, erythema, local swelling, and pain at the injection site. The effect of treatment lasted up to 12 months.

Conclusions: This pilot study showed that the treatment of tear trough deformity with hyaluronic acid gel filler was feasible, predictable and effective. All patients were very satisfied with their results.
\end{abstract}

Keywords: Hyaluronic acid, lower eyelid; Hyaluronic acid, injection; Hyaluronic acid, side effects; Filler; Treatment, tear trough; Face

\section{INTRODUÇÃO}

0 rejuvenescimento da região periorbital inferior passou a ser valorizado nas últimas duas décadas, tornando-se parte essencial da cirurgia cosmética da face. A correção cirúrgica da depressão dos sulcos nasojugal e palpebromalar é muito difícil, pois esta região é caracterizada por apresentar pele extremamente fina, estrutura óssea peculiar (arco zigomático), o ligamento or-

Trabalho realizado no Serviço de Plástica Ocular, Instituto da Visão, Universidade Federal de São Paulo - UNIFESP - São Paulo (SP), Brasil.

Médicos, Serviço de Plástica Ocular, Instituto da Visão, Universidade Federal de São Paulo UNIFESP - São Paulo (SP), Brasil.

Endereço para correspondência: Giovanni André Pires Viana. Alameda Jauaperi, 732 - São Paulo (SP) - CEP 04523-013 - E-mail: info@cliniplast.com

Os autores não apresentam qualquer tipo de interesse comercial no produto mencionado no texto Recebido para publicação em 24.11.2009

Última versão recebida em 18.11.2010

Aprovação em 19.11.2010

Nota Editorial: Depois de concluída a análise do artigo sob sigilo editorial e com a anuência dos Drs. José Byron Vicente Dias Fernandes e Célia Simōes C. de Oliveira Sathler sobre a divulgação de seus nomes como revisores, agradecemos suas participações neste processo. bitomalar, podendo ainda apresentar protrusão das bolsas de gordura através do septo orbital. Até o momento, métodos não invasivos para correção deste problema, tais como silicone líquido, polimetilmetacrilato, colágeno, entre outros, não têm demonstrado resultados consistentes ${ }^{(1-5)}$. Na tentativa de melhorar o contorno desta área, vários autores propõem uma abordagem conservadora no tratamento dos sulcos nasojugal e palpebromalar deprimidos através da injeção de ácido hialurônico ${ }^{(6-9)}$.

O objetivo deste estudo foi verificar a eficácia do preenchimento dos sulcos nasojugal e palpebromalar deprimidos por meio da injeção de ácido hialurônico e analisar as complicações observadas.

\section{MÉTODOS}

Foi realizado um estudo piloto, prospectivo com 10 pacientes consecutivos, aprovado pelo Comitê de Ética em Pesquisa da UNIFESP/EPM, recrutados do Serviço de Plástica Ocular do Departamento de Oftalmologia da UNIFESP, no período de junho de 2008 a agosto de 2008. Foram selecionados pacientes de ambos os sexos, com idade entre 25 e 60 anos, que apresentavam os sulcos naso- 
jugal e/ou palpebromalar deprimidos, com ausência de cirurgia ou trauma prévios na pálpebra inferior e que concordassem em participar desta pesquisa. Todos os casos que não se enquadravam nestes requisitos foram rejeitados. O tempo de acompanhamento mínimo deste estudo foi estabelecido como um ano.

Foi utilizado o ácido hialurônico (Restylane ${ }^{\circledR}$, Q-MED Brasil, Rio de Janeiro, RJ) na concentração de $20 \mathrm{mg} / \mathrm{ml}$. Todo paciente foi tratado pelo mesmo cirurgião (GAPV), tendo sido examinado no pós-operatório em intervalos regulares e fotografado no pré-operatório, no pós-operatório imediato, na $4^{\underline{a}}$ semana, no $6^{\circ}$ e no $12^{\circ}$ mês após o procedimento. Ao final deste período todas as fotos foram analisadas por profissional não ligado a esta pesquisa, visando verificar a eficiência da técnica em atingir seus objetivos. Para se obter uma avaliação quantitativa dos resultados, foi utilizada uma escala de graduação que classificou os resultados pré-e pós-operatórios, conforme proposto por Barton et al.(10).

A escala proposta por Barton e colaboradores, classifica esta região de acordo com as características anatômicas do local, variando de classe Zero (anatomia ideal) a classe Três (pior anatomia possível).

\section{TÉCNICA DE APLICAÇÃO}

Todos os pacientes foram posicionados sentados com o encosto da cadeira inclinado a aproximadamente 30\%, em ambiente bem iluminado. Foi realizada a assepsia local com álcool a 70\% e a morfologia da pálpebra inferior foi avaliada (Figura 1). A seguir foi aplicada uma camada de pomada tópica anestésica (Lidocaína, 25 mg; prilocaína, $25 \mathrm{mg}$ ) sobre a região a ser tratada e retirada após 20 minutos com o auxílio de uma gaze embebida em álcool a 70\%. A injeção do produto ocorreu com uma agulha de tamanho $30 \mathrm{G}(0,3 \mathrm{X}$ $13 \mathrm{~mm}$ ). A aplicação iniciou-se pela região mais lateral do sulco palpebromalar, seguindo em direção medial ao sulco nasojugal. A técnica de aplicação foi a de retroinjeção, ponto a ponto, com a agulha penetrando a pele em ângulo de aproximadamente $90^{\circ}$ (Figura 2). O produto foi depositado na região supraperiosteal em pequenos volumes a cada aplicação. Ao término da aplicação foi realizada massagem sobre a região tratada para melhor acomodação do produto.

Após a aplicação foi orientado ao paciente fazer uso de compressas umedecidas com solução fisiológica de $\mathrm{NaCl}$ 0,9\% durante 24 horas e uso de protetor solar (FPS 30). O paciente deveria retornar ao ambulatório para reavaliação após 7 dias, e se necessário, algum retoque seria realizado.

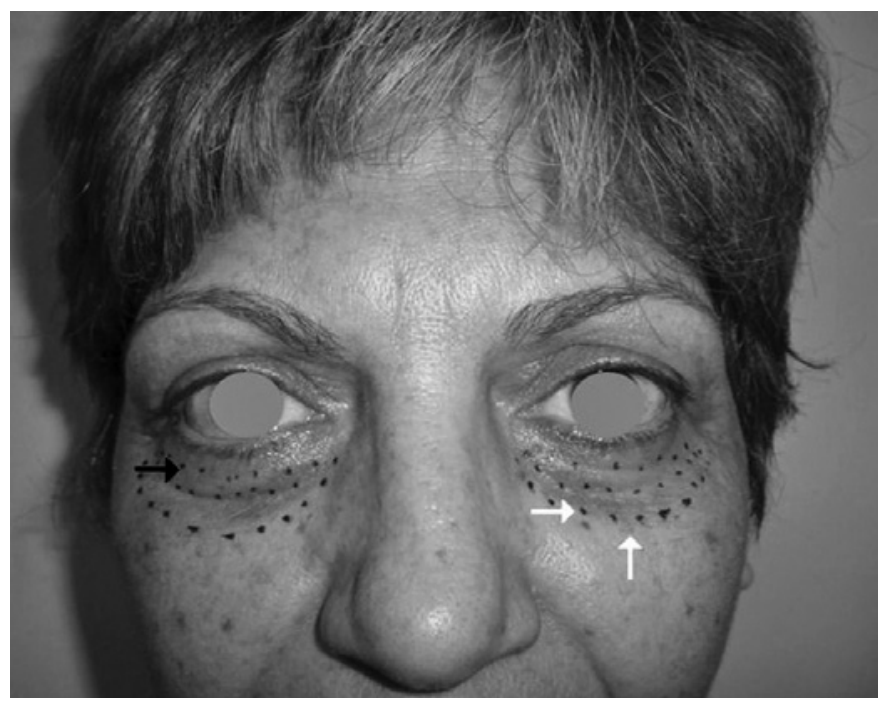

Figura 1. Esquema da marcação prévia. Seta preta- linha demarcando o rebordo orbital inferior. Seta branca - área a ser tratada com o ácido hialurônico.

\section{RESULTADOS}

Neste estudo foram incluídos 10 pacientes, todos do sexo feminino, com idade entre 29 e 58 anos (média 45,4 anos, DP=9,60). 0 tempo de acompanhamento variou entre 365 e 450 dias.

O volume injetado foi em média de $0,61 \mathrm{ml}(0,1-1,0 \mathrm{ml}$; $\mathrm{DP}=0,25)$ no lado direito e de $0,65 \mathrm{ml}(0,2-1,0 \mathrm{ml}$; $\mathrm{DP}=0,26)$ no lado esquerdo. $O$ resultado do preenchimento pode ser analisado na figura 3. Em duas pacientes foi necessário realizar um retoque na $4^{\underline{a}}$ semana após o tratamento, sendo realizada a injeção de 0,5 $\mathrm{ml}$ no lado direito e de $0,3 \mathrm{ml}$ no lado esquerdo da paciente número 1 e de $0,6 \mathrm{ml}$ em cada lado na paciente número 3.

A avaliação independente demonstrou que três pacientes foram classificados como classe 1, quatro como classe 2 e três como classe 3. Após um ano de tratamento, dentre os pacientes classificados como classe 1, dois foram avaliados como classe 0 e um não sofreu alteração de classe. Entre os pacientes da classe 2, dois foram classificados como classe 1 e dois não modificaram sua classe. Já entre os participantes classificados previamente em classe III, um foi avaliado como classe 1, outro como classe 2 e um não sofreu alteração alguma em sua classificação.

As complicações existentes foram equimose em $60 \%$ dos casos, edema local maior que 48 horas em um paciente e lesão cutânea semelhante à acne em um participante.

\section{DISCUSSÃO}

O produto ideal para preenchimento deve ser seguro, biocompatível, não imunogênico, facilmente obtido, não reabsorvível, de baixo custo e facilmente estocado. O ácido hialurônico (Restylane ${ }^{\circledR}$ ) foi escolhido por ser uma molécula presente em diferentes tecidos, entre eles no tecido conjuntivo, na derme, nas articulações e no vítreo; e por ser o produto que mais se aproxima do produto ideal ${ }^{(11)}$.

O ácido hialurônico é formado por uma cadeia longa polissacarídea, subdividido em unidades dissacarídeas repetidas de ácido

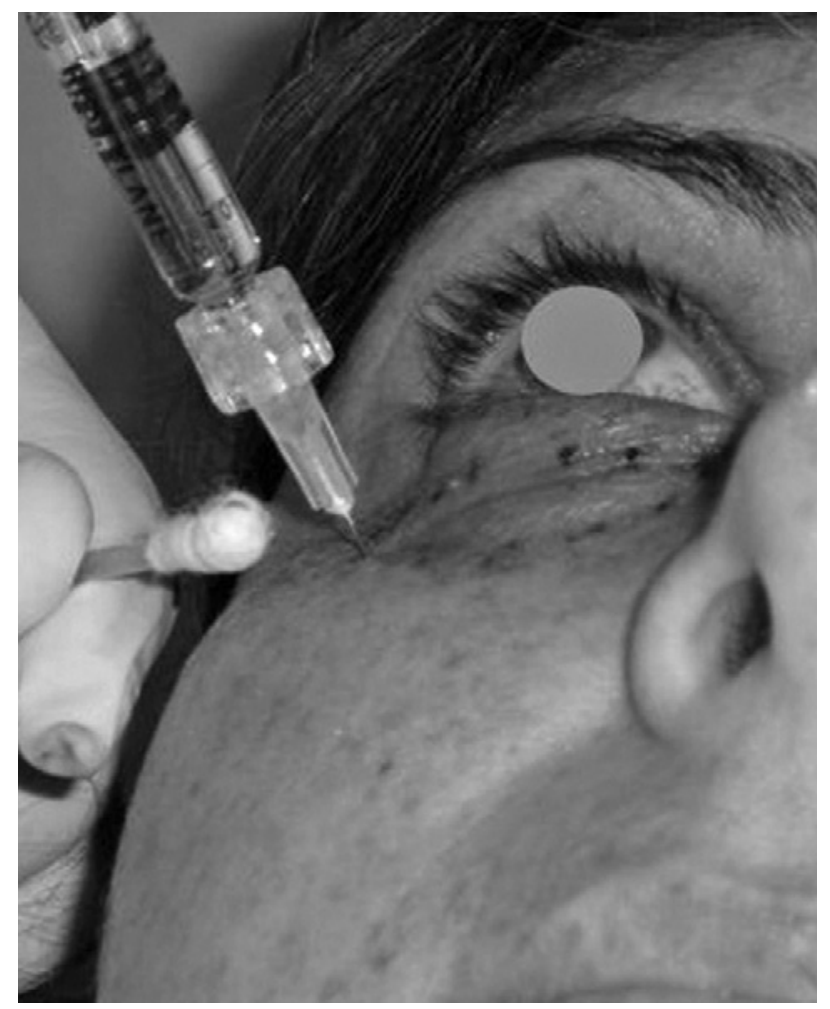

Figura 2. Aplicação através de retroinjeção de ácido hialurônico. 



Figura 3. Paciente feminino, 56 anos de idade. A) Antes do tratamento; B) Sete meses após a aplicação.

urônico e N-acetil-glicosamina. O Restylane ${ }^{\circledR}$ é um ácido hialurônico de origem não animal, obtido a partir da fermentação de cepas de Streptococcus (S. equi ou S. zooepidemicus) e estabilizado por processo químico de ligações cruzadas ("cross-linked")(11).

Goldberg et al. relataram sua experiência com o uso de Restylane ${ }^{\circledR}$ em 155 pacientes. O produto foi depositado em plano profundo (abaixo do músculo orbicular), formando uma figura tridimensional semelhante a um cone de palha ("haystack"). Relataram que para atingir o efeito desejado, entre 25 e 50 aplicações foram realizadas em cada sulco nasojugal(6).

Kane descreveu sua experiência com Restylane ${ }^{\circledR}$ no tratamento do sulco nasojugal, aplicando-o em um plano entre a pele e o músculo orbicular, criando pequenos cordões a cada aplicação (passada). Demonstrou que para se atingir o resultado ideal deveria ser feito em torno de 100 passadas por sulco nasojugal(7).

Steinsapir et al. descreveram que preferem depositar o ácido hialurônico em um plano supraperiosteal, entretanto, em alguns casos especiais alguns pacientes também seriam beneficiados por uma aplicação mais superficial, de modo semelhante ao proposto por Kane(7)

Outro relato mostra a aplicação de ácido hialurônico em plano médio (no músculo orbicular), com início da aplicação na região mais lateral do sulco nasojugal e depois progredindo em direção medial, devendo a velocidade de aplicação ser lenta e com pouca pressão(9).

Os autores, neste estudo piloto, preferiram a aplicação em plano profundo (plano supraperiosteal), com injeção de pequeno volume, de maneira retrógrada, ou seja, o produto só seria injetado quando a agulha estivesse sendo retirada, ficando o ácido hialurônico depositado abaixo do músculo orbicular, diminuindo a chance de irregularidades cutâneas ${ }^{(6)}$, e em alguns casos especiais, optouse por associar um preenchimento superficial ${ }^{(8)}$.

Observou-se que o nível de satisfação dos participantes com o resultado obtido após um ano de tratamento foi alto, uma vez que 
todos relataram ter visualizado mudança no formato de sua "olheira" (sulco nasojugal). Quando analisamos a avaliação realizada pelo observador independente, concluiu-se que 60\% dos pacientes apresentaram melhora na classificação do sulco nasojugal, entretanto, no restante dos pacientes, apesar de existir melhora cosmética visível, esta não foi a ponto de permitir a mudança de sua classificação. Verificou-se através do seguimento destes pacientes, que o efeito do preenchimento foi persistente após um ano ${ }^{(9)}$.

Todos os acontecimentos adversos, neste estudo piloto, foram leves, passageiros, autolimitados e se resolveram espontaneamente. Em um estudo com o Hylaform ${ }^{\circledR}$, observou-se a incidência de granuloma em 2\% dos casos; já em outra casuística com 4.320 casos com uso de Restylane ${ }^{\circledR}$ entre os anos de 1997 a 2001, obteve-se 0,02\% de incidência de reação de hipersensibilidade; em outro trabalho com 262.000 pacientes submetidos a tratamento com Restylane ${ }^{\circledR}$ no ano 2000, notou-se 0,06\% de incidência de eventos adversos, entre eles edema, hiperemia, prurido, equimose e irregularidade de contorno. Outro evento observado, neste mesmo estudo, foi o relato de desconforto no local da aplicação e do aparecimento de lesão tipo acne no local da aplicação, com incidência de 0,0005\% (11-15). Goldberg et al. relataram que os efeitos colaterais mais comuns foram equimose, irregularidade de contorno, edema persistente e alteração de coloração( ${ }^{(6)}$. Estes autores sugerem evitar o uso de Restylane $^{\circledR}$ em pacientes que apresentam edema periorbital frequente. Steinsapir et al. descreveram que as complicações mais frequentes encontrada por eles foram irregularidade de contorno e equimose ${ }^{(8)}$. Algumas das complicações mais temíveis quando se aplica qualquer substância na região periorbital, seria a injeção intra-arterial, com consequente lesão cutânea ou até mesmo amaurose. Contudo até o momento não há casos relatados de amaurose com o ácido hialurônico, apesar de existir casos com outros produtos, tais como silicone, colágeno, polimetilmetacrilato e corticóide ${ }^{(15-18)}$.

Os autores concluíram que este estudo piloto demonstrou que o tratamento dos sulcos nasojugal e palpebromalar com uso de ácido hialurônico se mostrou eficaz e previsível, com alto nível de satisfação dos pacientes e com resultado duradouro (maior que um ano). Os efeitos adversos foram autolimitados e de resolução espontânea. Com base neste estudo piloto, os autores propuseram o desenvolvimento de um estudo com maior número de pacientes e por um período maior de seguimento para avaliar a eficácia do ácido hialurônico.

\section{AGRADECIMENTOS}

Os autores agradecem o apoio da Q-MED Brasil pela doação do ácido hialurônico, sem o qual não haveria possibilidade de se realizar este estudo piloto.

\section{REFERÊNCIAS}

1. Carraway JH, Coleman S, Kane MA, Patipa M. Periorbital rejuvenation. Aesthet Surg J. 2001;21(4):337-43.

2. Stegman SJ, Chu S, Armstrong RC. Adverse reactions to bovine collagen implant: clinical and histologic features. J Dermatol Surg Oncol. 1988;14(1 Suppl):39-48.

3. Requena C, Izquierdo MJ, Navarro M, Martínez A, Vilata JJ, Botella R, et al. Adverse reactions to injectable aesthetic microimplants. Am J Dermatopathol. 2001:23(3):197-202.

4. Haneke E. Polymethyl methacrylate microspheres in collagen. Semin Cutan Med Surg. 2004:23(4):227-32.

5. Narins RS, Beer K. Liquid injectable silicone: a review of its history, immunology, technical considerations, complications, and potential. Plast Reconstr Surg. 2006;118(3 Suppl):77S-84S.

6. Goldberg RA, Fiaschetti D. Filling the periorbital hollows with hyaluronic acid gel: initial experience with 244 injections. Ophthal Plast Reconstr Surg. 2006;22(5):335-41; discussion 341-3.

7. Kane MA. Treatment of tear trough deformity and lower lid bowing with injectable hyaluronic acid. Aesthet Plast Surg. 2005;29(5):363-7.

8. Steinsapir KD, Steinsapir SM. Deep-fill hyaluronic acid for the temporary treatment of the naso-jugal groove: a report of 303 consecutive treatments. Ophthal Plast Reconstr Surg. 2006;22(5):344-8

9. Lambros VS. Hyaluronic acid injections for correction of the tear trough deformity. Plast Reconstr Surg. 2007;120(6 Suppl):74S-80S.

10. Barton FE Jr, Ha R, Awada M. Fat extrusion and septal reset in patients with the tear trough triad: a critical appraisal. Plast Reconstr Surg. 2004;113(7):2115-21; discussion 2122-3.

11. Matarasso SL, Carruthers JD, Jewell ML; Restylane Consensus Group. Consensus recommendations for soft-tissue augmentation with nonanimal stabilized hyaluronic acid (Restylane). Plast Reconstr Surg. 2006;117(3 Suppl):3S-34S; discussion 35S-43S. Comment in: Plast Reconstr Surg. 2006;117(3 Suppl):1S-2S.

12. Coleman SR; Plastic Surgery Educational Foundation DATA Committee. Cross-linked hyaluronic acid fillers. Plast Reconstr Surg. 2006;117(2):661-5.

13. Lemperle G, Rullan PP, Gauthier-Hazan N. Avoiding and treating dermal filler complications. Plast Reconstr Surg. 2006;118(3 Suppl):92S-107S. Review.

14. Nicolau PJ. Long-lasting and permanent fillers: biomaterial influence over host tissue response. Plast Reconstr Surg. 2007:119(7):2271-86

15. Rohrich RJ, Ghavami A, Crosby MA. The role of hyaluronic acid fillers (Restylane) in facial cosmetic surgery: review and technical considerations. Plast Reconstr Surg. 2007;120(6 Suppl):41S-54S.

16. Dreizen NG, Framm L. Sudden unilateral visual loss after autologous fat injection into glabellar area. Am J Ophthalmol. 1989;107(1):85-7.

17. Lemperle G, Romano JJ, Busso M. Soft tissue augmentation with artecoll: 10-year history, indications, techniques, and complications. Dermatol Surg. 2003;29(6):573-87; discussion 587.

18. Silva MT, Curi AL. Blindness and total ophthalmoplegia after aesthetic polymethylmethacrylate injection: case report. Arq Neuropsiquiatr. 2004;62(3B):873-4. 